\title{
Pensamiento filosófico de Ignacio Ellacuría y su función educativa-liberadora
}

Carlos Miguel Núñez Preciado ${ }^{1}$

Recibido en noviembre 2015, aceptado en marzo 2016

\begin{abstract}
Resumen
En esta presentación pretendo abordar una propuesta educativa liberadora conformada por tres elementos educativos extraídos del pensamiento filosófico de Ignacio Ellacuría. El pensamiento del jesuita ha sido abordado desde diferentes ámbitos: el teológico, el filosófico y socio-político, en cambio la cuestión educativa no se ha trabajado con la misma dedicación. Es por eso que este trabajo pretende cuestionar la validez educativa del pensamiento filosófico ellacuriano a fin de mostrar la pertinencia de la propuesta en la realidad socio-política de México. Vale la pena mencionar que el pasado 20 de octubre de 2015, el Congreso de las Américas sobre Educación Internacional (CAEI) otorgó de manera póstuma el Premio Interamérica a Ellacuría, reconociendo su labor en la educación superior. ${ }^{2}$

Palabras claves

Ellacuría, educación liberadora, educación, filosofía liberadora, praxis liberadora.
\end{abstract}

\begin{abstract}
:
In this presentation I intend to address a liberating educational proposal consists of three elements extracted educational philosophical thought of Ignacio Ellacuría. Jesuit thought has been approached from different areas: the theological, philosophical and socio-political, whereas the education issue has not worked with the same dedication. That's why this paper aims to question the validity of ellacuriano educational philosophical thought in order to show the relevance of the proposal in the socio-political reality of Mexico. It is worth mentioning that last October 20, the Congress of the Americas on International Education (CAIE) awarded posthumously the
\end{abstract}

1. Historiador independiente. Profesor e investigador salvadoreño. Instituto Salesiano de Estudios Superiores, México. E-mail: miguesdb.2310@gmail.com

2. http://www.uca.edu.sv/noticias/texto-3893 
90 Pensamiento filosófico de Ignacio Ellacuría y su función educativa-liberadora. Carlos Miguel Núñez Preciado

Inter-America Ellacuría Award, recognizing its work in higher education.

Keywords:

Ellacuría, liberating education, education, liberating phylosophy, liberating praxis.

Ellacuría fue un sacerdote jesuita español, naturalizado salvadoreño, rector de la Universidad Centroamericana “José Simeón Cañas" de El Salvador, la UCA; fue asesinado por el ejército salvadoreño hace veintiséis años. Es considerado por sus estudiosos como analista político, filósofo y teólogo de la liberación, ${ }^{3}$ se pueden distinguir en su pensamiento tres etapas con diferentes tendencias de un solo proyecto intelectual; la primer etapa consiste en la elaboración de una filosofía cristiana con validez para el siglo XX, en la segunda etapa Ignacio Ellacuría profundiza y divulga la filosofía zubiriana y la tercera comprende una filosofía propia con matices sociales y políticos que giran en torno a la liberación.

Este trabajo se enfocará en esta última etapa de filosofía liberadora, donde este pensamiento se entiende como una labor intelectual que se pone al servicio de los oprimidos; así mismo se asume la educación como un proceso de formación que brinda a la sociedad herramientas para que con libertad construya condiciones de vida más humanas; es por eso que el pensamiento filosófico abordado revela su carácter educativo.

En primera instancia, describiré brevemente en qué consisten los tres elementos educativos de la propuesta educativa-liberadora para después profundizarlos con mayor detenimiento y concluir con la relevancia que éstos pueden tener en la actualidad. La propuesta que les presento está constituida por la comprensión de la realidad, la praxis liberadora y la proyección social. El primer elemento educativo busca acceder a la realidad y estudiarla a profundidad; esta comprensión remite a un ejercicio epistemológico sin embargo cuenta a la vez con una carga ética implícita; este elemento se constituye con un ejercicio crítico y creativo de la realidad. El segundo elemento es una praxis liberadora que pretende transformar la realidad desde sus estructuras para que la sociedad apropie mayores posibilidades. Esta transformación consiste en una propuesta de libertad que mejore las condiciones de vida de una sociedad. El tercer aspecto educativo versa en una proyección social específica desde el ambiente universitario, en la cual se desarrollen estrategias a favor de los más oprimidos; fue en este ámbito donde Ellacuría encontró el lugar en el cual convergen los diferentes elementos de la propuesta educativa-liberadora.

3. Cfr. Valdés, Roberto. "La búsqueda filosófica inicial". Sobrino, Jon, Alvarado, Rolando, Ignacio Ellacuría "Aquella libertad esclarecida". San Salvador: UCA Editores, 1999. p. 61. 
Por tanto los tres elementos educativos que se proponen forman parte de un mismo proyecto educativo-liberador; estos elementos son constitutivos y cada uno necesita del otro para el adecuado desarrollo del proyecto. La praxis liberadora sólo se entiende desde el análisis que la comprensión de la realidad brinda y de igual modo, la proyección social no se realiza plenamente sin tomar en cuenta los dos elementos educativos anteriores.

Así, el objetivo de la siguiente presentación consiste en desarrollar los elementos de la filosofía ellacuriana que dan pauta para una propuesta educativa con función liberadora a fin de que la sociedad adquiera las condiciones para una vida más humana.

El primer elemento educativo a abordar es la comprensión de la realidad, que se debe de entender como una respuesta a las exigencias educativas y sociales que piden ingresar profundamente a la realidad, a sus estructuras como diría nuestro pensador. Este acceso a la realidad no es un simple acercamiento que permite obtener información sino un sumergirse en la realidad y hacerse cargo de ella. Es decir que la comprensión de la realidad no es un ejercicio que se realiza a distancia, el sujeto que la efectúa tiene un enfrentamiento con la realidad, que no sólo se reduce a un ejercicio epistemológico sino que tiene implicaciones éticas que se mencionarán más adelante.

El ser humano por su naturaleza abierta e inconclusa, al ingresar a la realidad se hace cargo de ella, no sólo la contempla sino que la analiza. Es por eso que el "hacerse cargo de la realidad", término extraído de la metafísica zubiriana se transforma en Ellacuría en un imperativo ético en donde la persona humana está obligado a cargar con la realidad. Esta obligación se explica desde el concepto zubiriano de religación, que expresa las relaciones metafísicas que el hombre tiene con su realidad.

Por tanto la obligación no sólo se entiende desde una perspectiva ética sino desde una profunda moral metafísica; donde la persona humana al estar ligada en una realidad y ser consciente de su implicación, es decir, al apropiarse de ella, tiene la responsabilidad moral (obligación) de transformarla a favor del bien común. Es por eso que este acto que en un primer momento es metafísico realiza un despliegue ético.

Esta realización ética se efectúa en la historia, ya que la realidad estudiada no puede ser abstracta; el elemento educativo de la comprensión exige en sí mismo una realidad concreta y por lo tanto histórica. Para Ellacuría, la historia no está hecha se construye, es un proceso de creación de posibilidades humanas; las cuales piden a la persona humana decisiones realizadas con libertad, es así que la realización de la historia tiene un carácter ético. 
92 Pensamiento filosófico de Ignacio Ellacuría y su función educativa-liberadora. Carlos Miguel Núñez Preciado

Para realizar este enfrentamiento con la realidad es necesario acudir a las cosas reales, ya que la realidad para Ellacuría guarda un doble proceso, es totalidad unificante y a la vez unidad totalizadora; mas no es un concepto idealista, es decir, aunque es abstracción hace referencia a las cosas reales y es en ellas donde se realiza la comprensión de la realidad.

Gracias a esto, se puede entender la labor estratégica de Ellacuría de llevar a sus alumnos al contacto directo con su propia realidad social, por ejemplo en comunidades marginadas; así cuando dijeran pobreza no se remitirían a las estadísticas socioeconómicas, "sino que tendrían presente el rostro de Micaela, Marta y Chon que perdieron cuatro de sus hijos por hambre y gustarían el sabor del café aguado y sin azúcar". ${ }^{4}$

Sin embargo, este elemento educativo no sólo consiste en acceder a la realidad de manera imparcial; al enfrentarse a ella se debe tener un claro sentido crítico que desenmascare las ideologizaciones dominantes, reductoras y falsificadoras de la realidad. Cabe especificar la diferencia entre ideología e ideologización, la primera es el pensamiento propio de una realidad social; en cambio la segunda es el ejercicio de una ideología para el dominio de un sector de la sociedad con el fin de conservar su status, por medio del encubrimiento de la realidad.

Es por eso que la búsqueda de la verdad no termina con el conocimiento de las cosas como son, sino que importa más cómo deberían de ser las cosas y por no serlo son falsas e injustas. " ${ }^{5}$ "La función crítica de la filosofía está orientada primordialmente a desenmascarar lo que de falso, injusto y desajustado contiene la ideología dominante [...]". ${ }^{6}$ Así, el estudio riguroso de la realidad realiza una crítica y fundamenta la desideologización que propone.

Por tanto, la prioridad teorética de la comprensión de la realidad tiene su implicación epistemológica y educativa en el "estar" en la realidad, ya que no es un análisis distante que pretende dar resoluciones abstractas y a priori. Esta comprensión de la realidad exige asumirla críticamente, sin embargo para lograr una acción liberadora no bastan las ideas, es necesario realizar un proceso que contrarreste las estructuras de opresión; ésto es lo que llevará al segundo elemento educativo: la praxis liberadora.

La praxis liberadora busca la justicia, actúa para favorecer el diálogo, brindar opciones, alternativas en la realidad, para que se viva con libertad y paz, donde se puedan construir los propios horizontes vitales, proyectos individuales y colectivos de vida digna. Se explica que "el esencial carácter práxico del

4. Fernández, David. Ignacio Ellacuría: vida, pensamiento e impacto en la universidad jesuita de hoy. Ciudad de México: Universidad Iberoamericana, 2006. pp. 22ss.

5. Cfr. Ellacuría, Ignacio. Filosofía ¿para qué?. El Salvador: UCA, 2003. p. 117.

6. Flores, Víctor. El lugar que da verdad: la filosofía de la realidad histórica de Ignacio Ellacuría. Ciudad de México, Universidad Iberoamericana, 1997. p. 192. 
hombre y de la vida humana se presenta éticamente como la necesidad de encargarse de la realidad para que sea lo que debe ser". ${ }^{7}$ Esta praxis que se puede considerar ética se convierte en liberadora encargándose de la realidad, es decir, dándole más posibilidades de ser. Es importante entender la liberación como "un proceso dinámico de transformación estructural de la realidad histórica que se va realizando a través de la apropiación de posibilidades individuales y sobre todo sociales"; ${ }^{8}$ el fundamento de esta liberación no es profundamente ético sino metafísico ya que estas posibilidades se encuentran en potencia en la realidad y la liberación se encarga de que se desarrollen realmente.

Así, en la búsqueda de la verdad no se puede limitar a una crítica de las ideologizaciones que encubren la realidad, ya que se critica con un propósito; es por eso la necesidad de formulaciones positivas que conviertan la crítica en creatividad.

La intención de conocer la realidad, asumirla y construirla implica éticamente un propuesta que la mejore a favor del bien común. Por tanto, esta praxis liberadora en primer momento es crítica a la realidad aprehendida, pero no se queda en la argumentación en contra de la ideología que enmascara la realidad sino que a la vez se crea una propuesta de libertad que aumente las posibilidades de vida en la realidad específica.

En otras palabras, el asumir la realidad de manera crítica no sólo significa destruir la ideologización que en sí misma es opresora e injusta; sino la creación de una propuesta liberadora que se encargue de un entorno específico con rostros personales a los cuales atender. En este elemento se hace presente el carácter ético del proceso educativo como la responsabilidad de transformar la realidad en la que se encuentra.

Es por eso que la función liberadora exige un serio análisis de una sociedad concreta, con herramientas válidas y efectivas para la época que se vive con el fin de responder adecuadamente a la realidad, evitando propuestas abstractas y a priori.

Para realizar estas exigencias es necesario abordar el tercer elemento de nuestra propuesta: la proyección social, que se desarrolla prioritariamente en un ambiente: el educativo. La educación es el momento central de una praxis liberadora ya que se considera como el esfuerzo colectivo de realización y perfeccionamiento humano, un momento esencial por la posibilitación y capacitación que brinda. Así, la educación como potenciación de sujetos humanos, tiene un alcance ético y liberador, que busca formar sujetos transformadores de la realidad.

7. Samour, Héctor, Voluntad de liberación, El pensamiento filosófico de Ignacio Ellacuría. El Salvador: UCA, 2002. p. 118.

8. Flores, Víctor. op. cit. p. 225. 
Para Ellacuría, la liberación histórica consistirá, en definitiva, en posibilitar que los seres humanos se vayan constituyendo en agentes, actores, y autores de su propio proceso histórico [...] En este sentido, 'el fin' de la historia sería en que hombres libres condujesen libremente el proceso estructural [de la misma]. ${ }^{9}$

Esta labor que se menciona no es un proyecto meramente intelectual, Ellacuría lo asumió como proyecto de vida crítico y creativo a favor de los oprimidos llevándolo a su propia muerte. Este proyecto intelectual estaba inmerso en el ámbito educativo y fue sostenido por un eje fundamental: la incidencia de la institución universitaria en la realidad histórica.

Como ya se ha dicho, el ambiente educativo fue considerado por nuestro pensador como un laboratorio de la verdad; este ambiente debe en un segundo momento favorecer la libertad la cual está unida intrínsecamente a la verdad, que es la que genera la libertad pero no de manera consecuente, se requiere una clara intención liberadora, ya que esa misma verdad puede ser usada para la ideologización.

El responder a las exigencias de la liberación "exige de la universidad un permanente acto creador, que implica una gran capacidad intelectual colectiva, pero sobre todo un gran amor a las mayorías populares, un indeclinable fervor por la justicia social y un cierto coraje para superar los ataques, las incomprensiones $\mathrm{y}$ las persecuciones [...]". ${ }^{10}$

Es en el ámbito universitario donde Ellacuría encontró el lugar que da verdad y a la vez aquél que da libertad a los sectores oprimidos. Su propuesta que integra la teoría y la praxis liberadoras tiene una incidencia real gracias a la proyección social, que él la entendía como encargarse de la realidad.

Así, siendo los analistas universitarios los que se enfrentan epistemológica y éticamente a la realidad y cargan con ella "sería un error partir de la idea de que la universidad -especialmente la privada- cumple su misión manteniéndose neutral ante los problemas que afligen a la sociedad y, especialmente, a los menos favorecidos". ${ }^{11}$

Ellacuría afirma que la universidad debe asegurar los derechos fundamentales de las mayorías populares y además "debe tener como horizonte teórico y práxico de sus actividades estrictamente universitarias el de la liberación y del desarrollo de esas mayorías y esto de un modo preferencial". ${ }^{12}$

9. Ibídem, p. 324.

10. Ellacuría, Ignacio. op. cit. p. 219.

11. Vázquez, Rodolfo. "Educación liberal y democrática". En Hoyos, Vásquez Guillermo. Filosofía de la Educación. Madrid: Trotta. p. 226.

12. Ellacuría, Ignacio. op. cit. p. 205. 
Por último, la proyección social es donde el trabajo teorético y la praxis liberadora se concretizan en estrategias puntuales. Ellacuría logró integrar tanto la comprensión de la realidad, como el encargarse de la realidad, en el ambiente universitario como una institución educativa en la cual convergen los tres elementos del proceso educativo-liberador.

La intención educativa del proceso liberador lleva a los educandos a enfrentarse con una realidad como la de los cuarenta y tres estudiantes desaparecidos en Ayotzinapa; este proyecto los lanza a conocer a fondo el conflicto y criticar las posturas políticas que lo encubren. Además, es necesario estar con los que sufren la realidad compadeciéndose y al mismo tiempo brindando propuestas creativas que posibiliten una vida más humana; el cargar con la realidad consistiría en darles las condiciones necesarias para expresarse libremente y puedan exigir justicia como ciudadanos. De igual manera, encargarse de esta realidad exige atender las necesidades básicas de las personas afectadas, en este caso los familiares de los desaparecidos para que, a pesar del conflicto, puedan construir una vida con dignidad.

En síntesis, el proceso educativo-liberador contempla un riguroso análisis teorético con prioridad en el primer elemento de comprensión de la realidad; una praxis coherente con la teoría, que se enfatiza en el segundo paso; y una incidencia específica y real en una sociedad con el tercer elemento del proceso educativo-liberador. No significa que el tercer elemento es el único que tiene contacto directo con la realidad; todo el proceso está en inmerso en la realidad asumiéndola, construyéndola y transformándola.

Para concluir, vale la pena afirmar que el pensamiento de Ignacio Ellacuría además de ser profundamente filosófico, teológico, político y social tiene un carácter educativo que resulta válido para la actual sociedad mexicana por el serio análisis que propone desde la misma realidad y la desideologización que plantea con la finalidad de brindar posibilidades reales a las personas, a fin de que lleguen a ser libres y por consiguiente plenamente humanos.

\section{Bibliografía}

Ellacuría, Ignacio. Escritos universitarios. San Salvador: UCA Editores, 1999. pp. 219.

Fernández, David; Orozco, José Morales. Ignacio Ellacuría: vida, pensamiento e impacto en la Universidad Jesuita de Hoy. México: Universidad Iberoamericana, 2006, pp. 82.

Flores, Víctor. El lugar que da verdad: la filosofía de la realidad histórica de Ignacio Ellacuría. Ciudad de México, Universidad Iberoamericana, 1997. pp. 225.

Gimbernant, José; Gómez, Carlos. La pasión por la libertad, Homenaje a Ignacio Ellacuría. EVD. pp. 13.

Hoyos, Vásquez Guillermo. Filosofía de la Educación. Madrid: Trotta. pp. 352.

Instituto de Derechos Humanos Ignacio Ellacuría SJ. Hacerse cargo de la realidad, Primer 
aniversario. México: Universidad Iberoamericana Puebla, 2011. pp.172.

Muñoz, Diego, La esperanza humana como apertura a la trascendencia: una propuesta de inspiración zubiriana, México: Universidad Pontificia de México, 2005. pp. 81

Samour, Héctor. Voluntad de liberación: el pensamiento filosófico de Ignacio Ellacuría. El Salvador: UCA Editores, 2002. pp. 448.

Sobrino, Jon, Alvarado, Rolando, Ignacio Ellacuría “Aquella libertad esclarecida”. San Salvador: UCA Editores, 1999. pp. 61.

Villalpando, José Manuel. Filosofía de la Educación. México: Porrúa, 1992. pp. 297. 